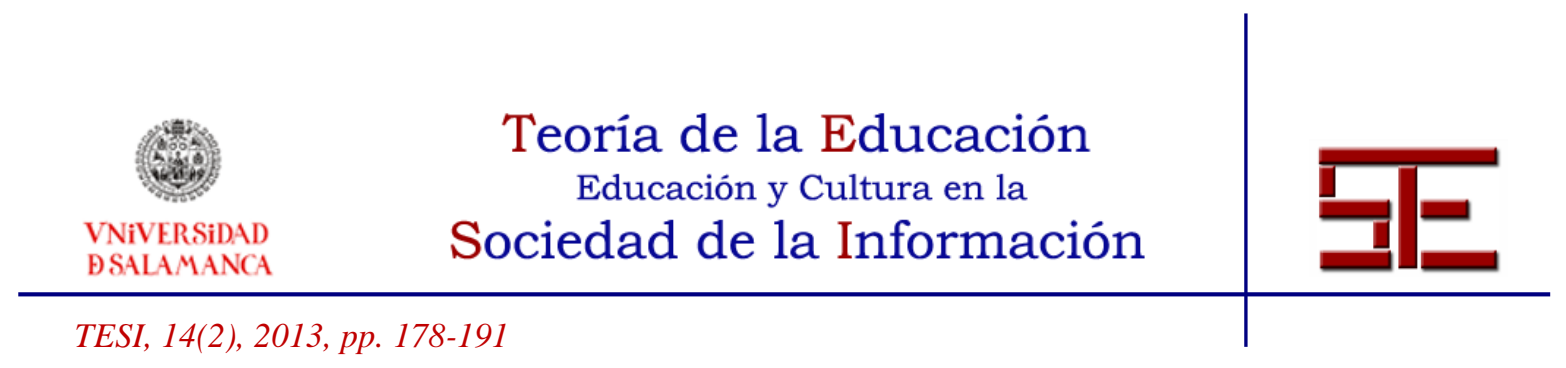

\title{
TENSIONES Y DILEMAS EN LA EDUCACIÓN DE PERSONAS ADULTAS
}

Resumen: De una sociedad asentada en la racionalidad "moderna" en que la educación de las personas adultas buscaba alcanzar la emancipación social, hemos evolucionado hacia una sociedad legitimada por una nueva racionalidad en la que la educación de las personas adultas se convierte en una mercancía al servicio del nuevo mercado global y de los nuevos valores culturales postmodernos. Obviamente, estos cambios conllevan la aparición de "nuevos discursos" que tratan el concepto de la educación de personas adultas como sinónimo de otros conceptos más pragmáticos y con una finalidad resolutiva de los problemas del mundo actual. Aprender significa responder de manera eficiente a las rápidas y cambiantes necesidades del mercado. La educación se transforma en educación a lo largo de la vida y el lugar de trabajo actúa como una organización de aprendizaje.

Palabras clave: educación de adultos; neoliberalismo; postmodernismo; sociedad del conocimiento.

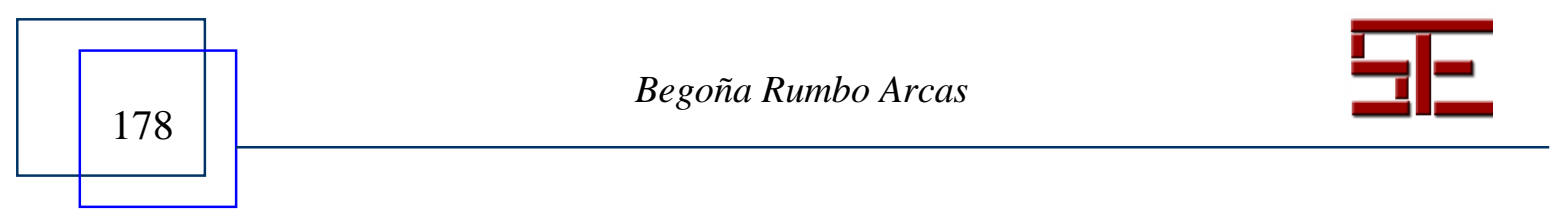




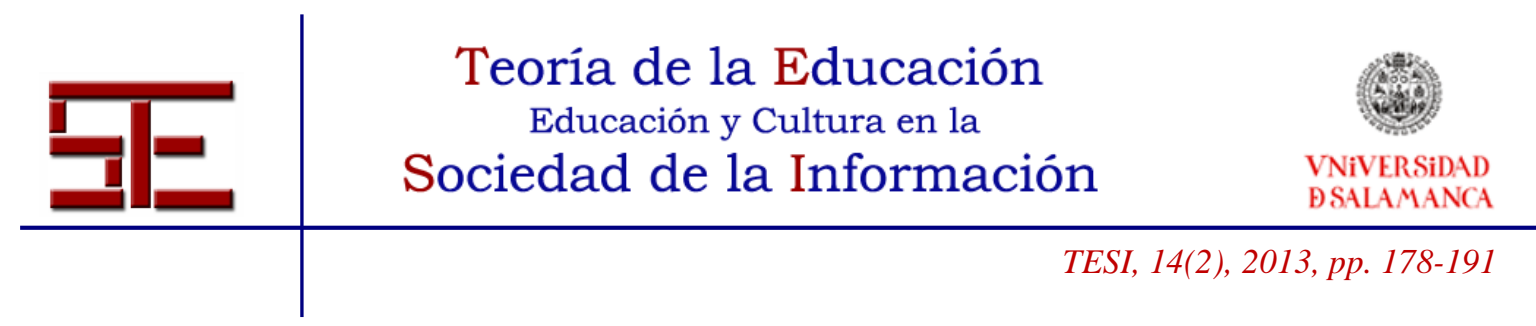

\title{
TENSIONS AND DILEMMAS IN ADULT EDUCATION
}

\begin{abstract}
In a society based on rationality "modern" in the adult education wanted to achieve social emancipation, we have evolved into a society legitimized by a new rationality in which adult education becomes a commodity service the new global market and new postmodern cultural values. Obviously, these changes have the appearance of "new discourse" that deal with the concept of adult education as synonymous with other concepts and a more pragmatic purpose of solving the problems of the present world. Learning means to efficiently respond to the rapid and changing market needs. Education becomes lifelong learning and the workplace acts as a learning organization.
\end{abstract}

Key words: Adult education; neoliberalismo; postmodernismo; knowledge society.

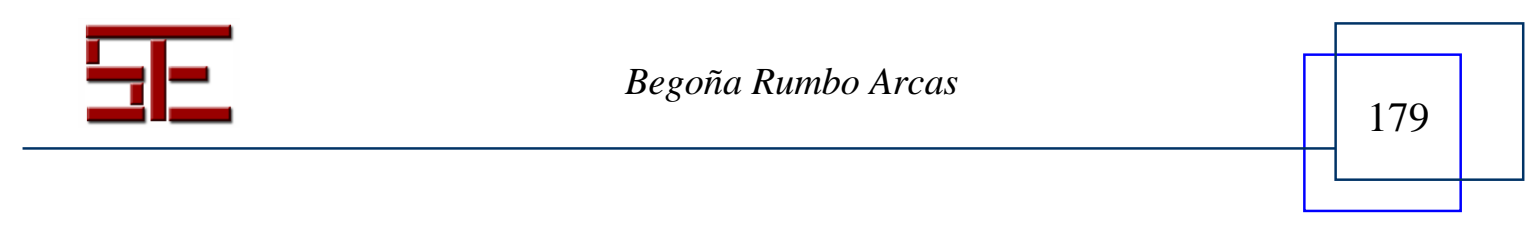




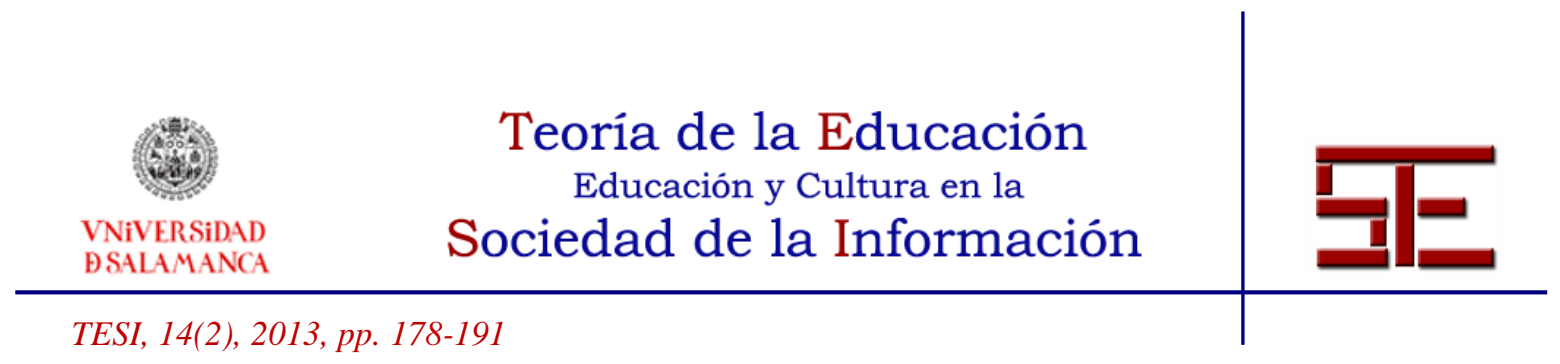

\section{TENSIONES Y DILEMAS EN LA EDUCACIÓN DE PERSONAS ADULTAS}

Fecha de recepción: 18/12/2012; fecha de aceptación: 10/05/2013; fecha de publicación: 30/07/2013

Begoña Rumbo Arcas

begona.rumbo@udc.es

Universidad de A Coruña

\section{LA RACIONALIDAD MODERNA Y LA EDUCACIÓN DE LAS PERSONAS ADULTAS}

Parece haber consenso en que estamos asistiendo a profundos cambios económicos, tecnológicos y culturales. Como afirma Shahrzad Mojab (2001), la mayoría de las economías industriales occidentales se preocuparon durante el último cuarto de siglo XX por dar sentido a los cambios que afectaban al sistema entero, tanto a nivel nacional, como internacionalmente. Se teoriza sobre el tránsito de una sociedad basada en una economía capitalista centrada en la producción, hacia un sistema centrado fundamentalmente en el conocimiento y la información.

Sin embargo, hay menos acuerdo entre los teóricos respecto a si estos cambios constituyen una continuidad de la modernidad o si, por el contrario, estamos ante una nueva condición postmoderna como consecuencia del fracaso de la anterior.

Aunque es muy difícil señalar el comienzo exacto de la denominada "modernidad", algunos autores la identifican con un período histórico cuyos orígenes se remontan a la Ilustración. La época ilustrada fue testigo de los comienzos de un proceso de modernización social originado por un interrumpido proceso de industrialización y la aparición del Estado Moderno. Como señala José Gimeno (1998), las dos mayores filosofías políticas de la Ilustración fueron: el liberalismo clásico, que privilegiaba la razón y el conocimiento de las disciplinas científicas, como principio de autoridad moral y de acción; y el marxismo, como filosofía igualadora a través de la escolarización universal.

Desde el siglo XIX, y especialmente en el XX, el proyecto de una escuela pública se consideraba la respuesta idónea para lograr la igualdad, expandir la fe en la razón y proporcionar las competencias, actitudes y valores necesarios para el ejercicio de una ciudadanía responsable. De esta manera, el desarrollo de los sistemas escolares estaba ligado a la formación del Estado Moderno, que actuaba como agente de cohesión social y

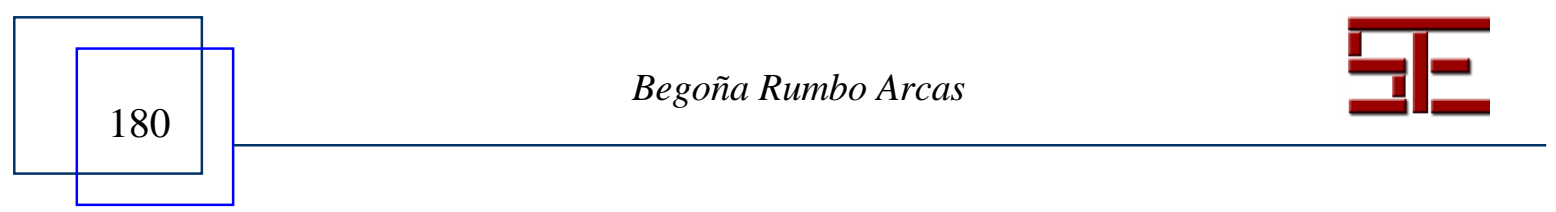




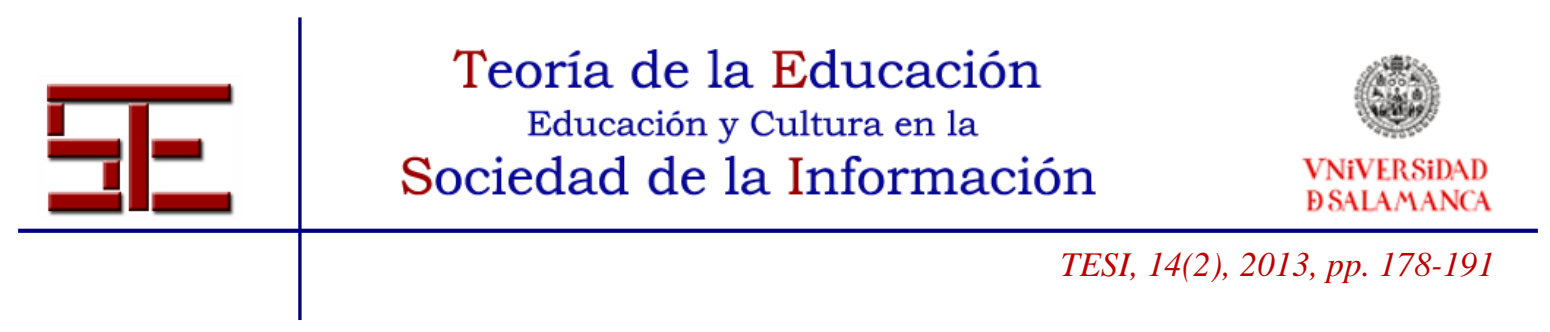

garantizaba el cumplimiento de los derechos a través de su acción benefactora y pretendidamente igualadora. En varios países, la educación de personas adultas se convirtió en un instrumento de emancipación de las clases populares que habían sido privadas de una escolarización regular durante su infancia y adolescencia.

Desde el punto de vista económico, el comienzo de la modernidad se produce cuando la familia y el lugar de trabajo se separan a causa de la concentración de la producción en las fábricas. La economía basada en el trabajo manual es reemplazada por la industria y la manufactura. Esta nueva organización laboral, inspirada en los principios científicopositivistas, se caracterizaba por la fuerte segmentación y especialización de los trabajadores y las trabajadoras, la mecanización de las tareas y el control de los tiempos de producción. Esto condujo a un modelo de organización laboral fuertemente burocratizado en el que cada trabajador y trabajadora tenía asignada su tarea de antemano, convirtiéndose en autómatas ejecutores del trabajo que otros planifican para ellos.

La traslación de este modelo empresarial al sistema escolar no se hace esperar. Legitimado por el conductismo, el conocido modelo tecnológico/positivista tendría interesantes consecuencias en la educación de las personas adultas. La robotización laboral era suficiente para hacer frente a las demandas poco cambiantes del mercado. Consecuentemente, la formación ocupacional de los trabajadores y trabajadoras era innecesaria, al convertirse la experiencia laboral en la única fuente de formación y aprendizaje.

Paralelamente, la educación se transforma de una actividad humana a una institución cultural reglada. La aparición de la escuela conllevó la separación entre la infancia y la adultez, quedando la vida de las personas dividida en dos etapas diferentes con roles sociales específicos. El rol del aprendiz y el rol del trabajador. Los conocimientos adquiridos en la escuela eran suficientes para, una vez finalizada la edad escolar, desenvolverse en la vida adulta. En un contexto en el que se reconoce que hay una edad para aprender y otra para trabajar, el único ámbito reconocido de la educación de personas adultas era la alfabetización, entendida ésta como una tarea de compensación de la ausente o insuficiente escolaridad recibida en el pasado.

Por su parte, a nivel político, la aparición del Estado Moderno no sólo había venido a cumplir su función cohesionadora y garante de mejoras sociales sino, que, como afirmaban las teorías sociológicas de la reproducción, también había supuesto un poderoso instrumento controlador y legitimador de las desigualdades sociales. De este modo, la función de

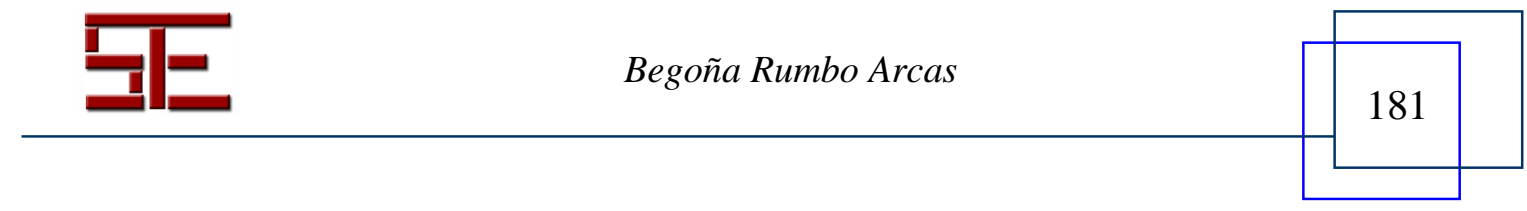




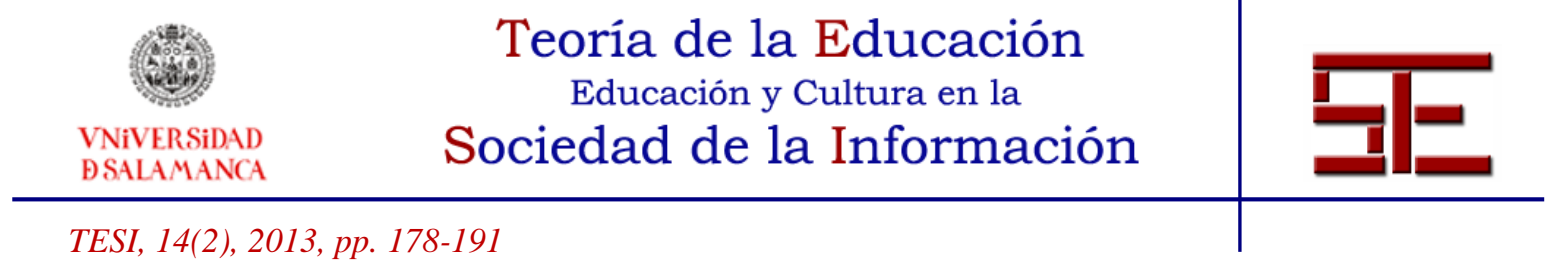

protección social se subyugaba a la función de control social. Función, por otra parte, desempeñada por la escuela a través de la transmisión de la cultura "valiosa". El ideal moderno del Estado de universalizar los derechos parecía estar muy lejos de ser cumplido.

\section{LA ADOPCIÓN MERCANTILISTA DE LA EDUCACIÓN DE LAS PERSONAS ADULTAS}

Históricamente, Crowther (2004) presenta el discurso de la educación a lo largo de la vida entre dos polos: el de la emancipación y la adaptación. Por una parte, la educación de personas adultas se sumerge y participa del debate educativo progresista de los años 6070 en el que la educación era concebida como un servicio para la creación de una sociedad en la que los individuos se desarrollan, crecen y se orientan por un bien común a través de políticas del Estado de Bienestar. Esa creencia todavía sigue vigente en una importante parte de los discursos teóricos que se hacen sobre la educación de las personas adultas. Inspirados en las teorías críticas de la educación, se sigue ese ideal utópico y esperanzador de que la educación es un poderoso instrumento nivelador e igualador de las desigualdades e injusticias sociales.

Por otra parte, el contexto económico actual nos lleva a confirmar una creciente influencia de las políticas neoliberales en los nuevos discursos sobre la educación a lo largo de la vida. La educación de las personas adultas adquiere un lugar importante, en tanto sus destinatarios sustentan la dinámica de los mercados en sus dos dimensiones: como consumidores y como productores. La educación de las personas adultas deja de ser un proyecto de emancipación y cambio social para convertirse en servidora del mercado, con la finalidad de mejorar destrezas para incrementar el trabajo productivo y aumentar la competitividad.

Se hace necesario satisfacer el nuevo modelo de producción neoliberal, más flexible y colegiado, en donde se dice que los trabajadores y las trabajadoras tendrán mayor libertad y autonomía en los procesos de producción. La formación en el lugar de trabajo, el reciclaje, el trabajo por objetivos, la resolución de problemas, etc., acaban convirtiéndose en la jerga educativa más frecuente en los discursos y en las ofertas formativas de la educación de las personas adultas contemporánea. Ésta se transforma en uno de los mejores instrumentos formativos que tiene el mercado global para incrementar la capacidad de los trabajadores y las trabajadoras de forma que puedan resultar más eficientes para las organizaciones y obtener así mayores beneficios económicos.

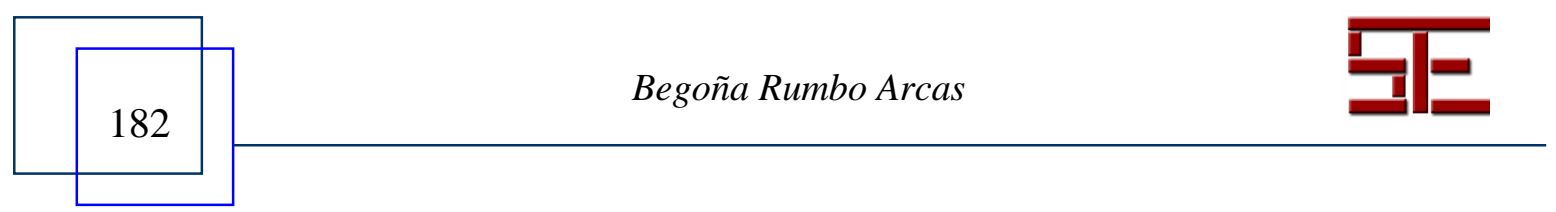




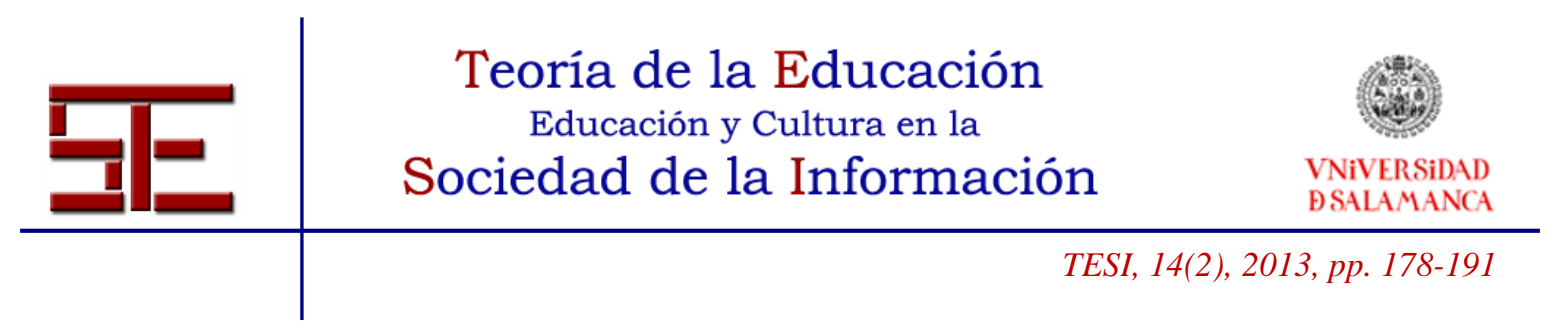

Sin embargo, algunos estudios vienen a cuestionar la relación directa entre invertir en educación de personas adultas y el aumento de la productividad y, consecuentemente, el incremento de los ingresos económicos de sus trabajadores. Es el caso, por ejemplo, de la investigación que desarrolló Shahrzad Mojab (2001) para analizar las políticas públicas canadienses y su relación con la prosperidad económica del país. Esta autora llega a la conclusión de que en el momento de entrar en el mercado de la información, el 40\% de mujeres inmigrantes "trabajadoras del conocimiento", con "altas capacidades" y con una experiencia considerable en su país de origen, o bien se quedaban fuera como desempleadas, o bien fueron presionadas para aceptar trabajos por debajo de su preparación. Consecuentemente, se podría llegar a concluir que el actual modelo económico capacita o descapacita la mano de obra en función de variables como: dificultades con el idioma oficial del país, la raza, el género, etc.

En este sentido, Torres (1996) menciona que uno de los aspectos más importantes para estudiar las relaciones entre educación de las personas adultas-productividad-nivel de ingresos es lo que denomina la "teoría de la segmentación del mercado laboral". De acuerdo con esta teoría, las condiciones del mercado laboral pueden ser entendidas como los resultados de cuatro procesos de fragmentación: a) segmentación de los trabajos de "primera" y "segunda" categoría; b) segmentación con el sector primario; c) segmentación por raza; d) segmentación por género.

Según este autor, la segmentación de los trabajos de "primera" o "segunda" clase reside en que " los trabajos de primera" requieren un desarrollo estable de los hábitos laborales, las destrezas son a menudo adquiridas en el propio lugar de trabajo, los salarios son relativamente altos y existen jerarquías laborales. Los "trabajos de segunda" no requieren con frecuencia hábitos laborales estables, los salarios son más bajos y las posibilidades de ascenso son pocas. Estos trabajos (aunque no en exclusiva) son ocupados por minorías, mujeres y jóvenes.

Si analizásemos la oferta y la demanda de actividades formativas de educación para personas adultas en nuestro contexto, tal vez podríamos llegar a compartir las conclusiones de los anteriores estudios y afirmar que la educación de personas adultas mayoritariamente prepara a las personas para aumentar sus posibilidades de entrar en los mercados laborales de "segunda", lo que nos invita a ser cautelosos a la hora de afirmar la relación directa entre educación de personas adultas-productividad y nivel de ingresos. A lo que debemos añadir, por otro lado, que no siempre las personas que más necesitan realizar actividades formativas para mejorar sus condiciones de bienestar son las que más participan en actividades de

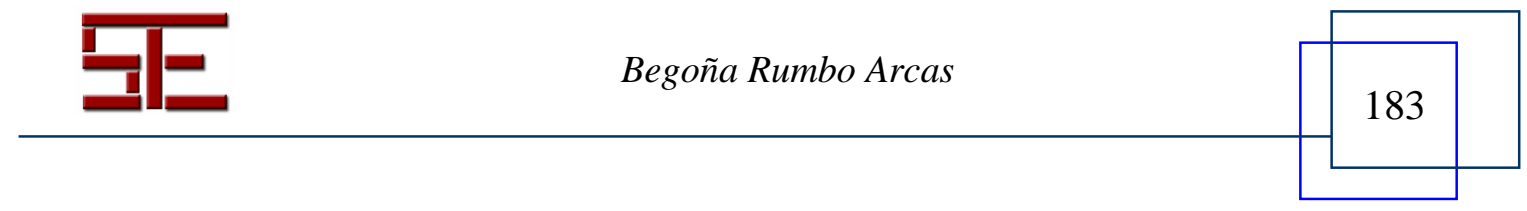




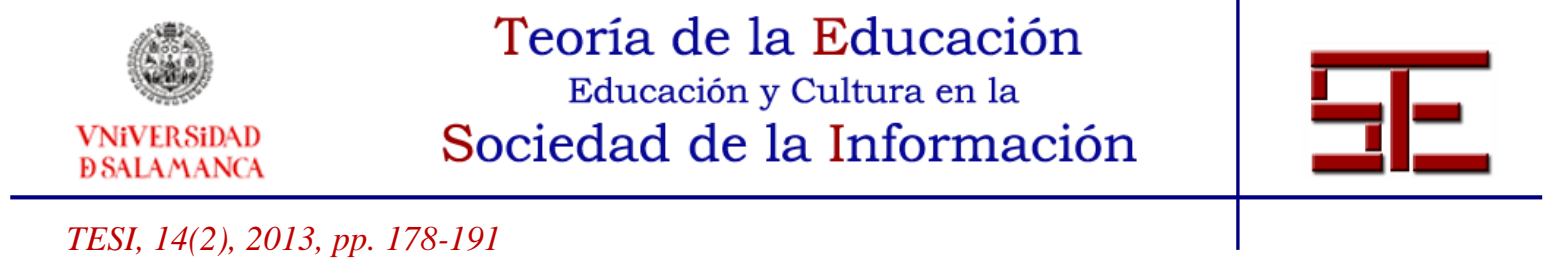

educación de personas adultas.

De esta manera, el último Informe europeo sobre la educación formal de Adultos en Europa: políticas y prácticas, realizado por la red Eurydice, viene a confirmar lo dicho anteriormente, pudiendo observarse como en aquellos países donde el porcentaje de la población adulta poco cualificada es relativamente alto, la participación en actividades formativas formales es muy baja, es el caso, p. ej., de Portugal (7\%), España (6\%), Malta (5\%), Italia (4\%) y Grecia y Turquía (2\%).

La situación anteriormente descrita se hace todavía más preocupante en una sociedad descrita como sociedad del conocimiento, en la que su adquisición se hace imprescindible, no tanto por su calidad, sino por su productividad. La esperanza de algunos teóricos de que la sociedad del conocimiento iba a suponer una oportunidad para generar pensamiento crítico y servir de contrapunto a los efectos perniciosos de la globalización se va debilitando a favor de lo que algunos autores empiezan a calificar como "la sociedad de la ignorancia". Cada vez se hace más difícil poder transformar la información en conocimiento, porque las personas no disponemos de suficientes capacidades para procesar, integrar, entender e interpretar la gran cantidad de información que se genera en la sociedad y, consecuentemente, para algunos se nos hace cada vez más difícil poder integrarnos en ella. Podríamos afirmar, de acuerdo con Mayos (2011a), que estamos ante una nueva exclusión social, "la exclusión cognitiva" de aquellas personas que no han tenido la capacidad y oportunidad de incorporarse a la revolución tecnológica, que se impone e invade todos los órdenes de nuestra vida y de la que resulta difícil poder evadirse.

Como bien explica Ettore Gelpi (1990) nuevas divisiones potencialmente peligrosas separan los trabajadores y trabajadoras jóvenes de los adultos y adultas, en el mundo educativo y laboral. Separación que obedece al tipo de tecnología que utilizan y al acceso o no a nuevos conocimientos o tecnologías. Lo cual significa la posibilidad, o no, de trabajos cualificados, niveles superiores de salarios y de movilidad social y educativa.

\subsection{La educación de personas adultas como objeto de consumo}

Otro de los rasgos distintivos de la sociedad contemporánea es la importancia que adquiere el consumo como valor cultural. El consumo configura identidades donde lo que se consume funciona como una seña de identidad, bien para la diferencia con los otros, bien para la solidaridad con los que consumen lo mismo.

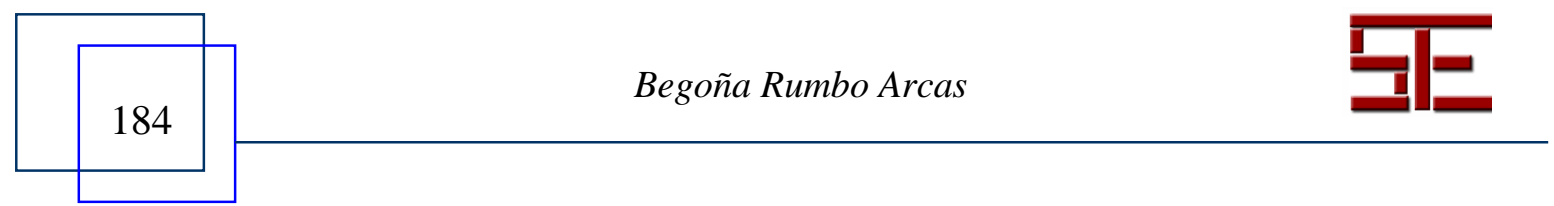




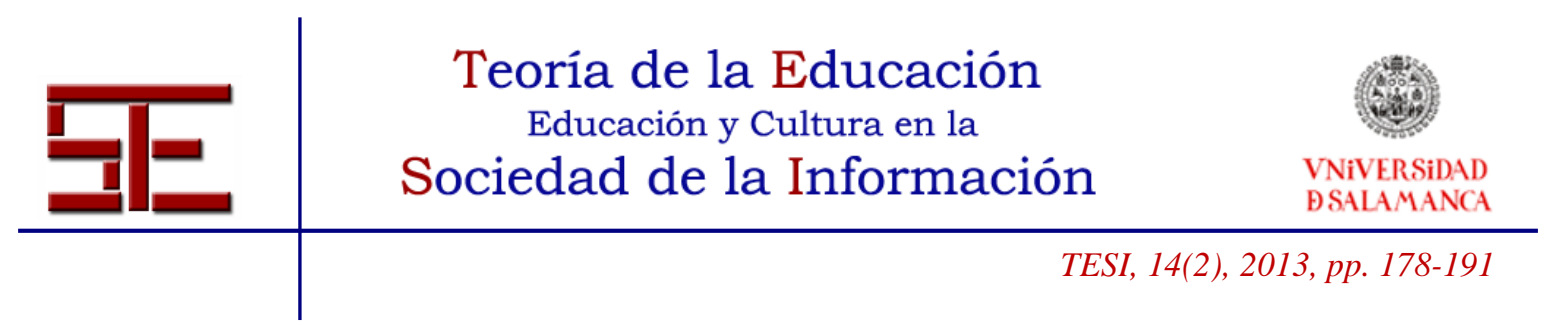

La cultura del consumo es semiótica en la medida en que los artículos de consumo se convierten en un conjunto de señales que nos permiten suponer la posición social de los individuos y grupos. Ya no sólo es importante ofrecer oportunidades para que las personas adultas puedan desempeñar un trabajo de forma eficiente. En una economía de mercado que nos atrapa en la cultura de las marcas, y en donde la diferenciación entre el "ser" y el "tener" es cada vez menor, los individuos compran su identidad.

Desde esta óptica consumista, la educación de las personas adultas se transforma en un artículo de consumo más, con diferentes semióticas, diferentes significados, diferentes posibilidades, estando a su vez determinada por el inevitable avance tecnológico y sus exigencias para aprender a adaptarse a las condiciones del cambio social. Para las personas adultas formarse es importante si esa formación actúa como un instrumento de diferenciación de otros o como una señal de identificación con otras "personas educadas".

Robin Usher (2007) afirma que, en el actual contexto, el aprendizaje ya no está predefinido por una metas prefijadas, como en un proyecto educativo moderno, sino que, por el contrario, el aprendizaje adopta una gran variedad de formatos consumibles en los supermercados de la cultura donde, además, compiten con los del ocio y el entretenimiento; lo que nos lleva, en numerosas ocasiones, a caer en la tentación de confundir cultura con todo lo que sea comercial, hasta el punto que retrata Vargas Llosa en su obra La civilización del espectáculo, en la que,

... es normal y casi obligatorio que la cocina y la moda ocupen buena parte de las secciones dedicadas a la cultura y que los Chefs y modistos y modistas tengan ahora el protagonismo que antes tenían los cientificos, los compositores y los filósofos. Los hornillos y las pasarelas se confunden dentro de las coordenadas culturales de la época con los libros, los conciertos, los laboratorios y las óperas, así como las estrellas de la televisión y los grandes futbolistas ejercen sobre las costumbres, los gustos y las modas, la influencia que antes tenían los profesores, los pensadores y (antes todavía) los teólogos (Vargas Llosa, 2012, 37).

Como anuncia Subirats (2011), uno de los problemas epistemológicos que se plantean en la sociedad del conocimiento es que al romper con el modo tradicional de ordenar jerárquicamente los saberes, todos los conocimientos se sitúan en el mismo plano de igualdad en cuanto a su validez, lo que nos lleva a un peligroso relativismo que pudiera justificar la existencia de prácticas manipuladoras y opresivas.

\section{NUEVOS RETOS PARA LA EDUCACIÓN DE LAS PERSONAS ADULTAS EN EL ESCENARIO SOCIAL CONTEMPORÁNEO}

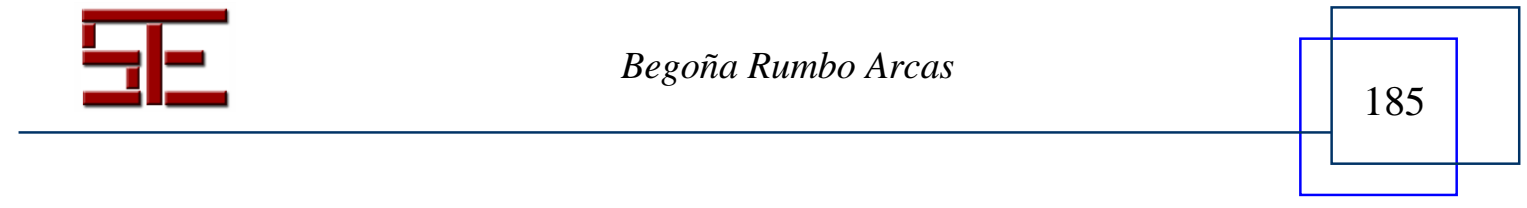




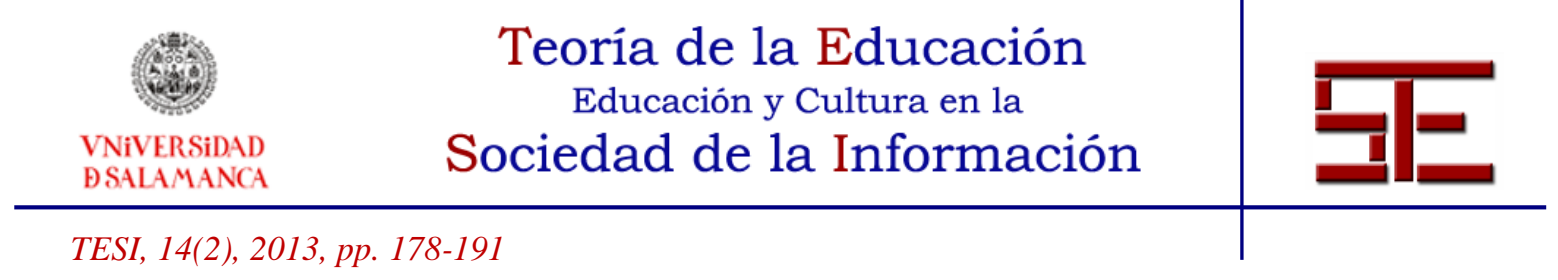

Como afirma Stephen Kemmis (1999-2000) si nuestra sociedad ha cambiado de una forma tan espectacular y si nuestras formas de experimentar el mundo han cambiado con ella, esos cambios deben tener unas consecuencias muy significativas para el desarrollo de la vida social y de la educación.

Las "grandes narrativas" modernas, como el liberalismo clásico potenciador de las libertades individuales, el marxismo como filosofía igualadora, la búsqueda de la verdad y una fe absoluta en la cientificidad como condición indispensable para que el mundo progrese, conducen a un escepticismo entre los defensores del postmodernismo, que ven como esos principios no han servido para cambiar el mundo, ni para explicar los desastres de la humanidad. Es por ello por lo que el pensamiento postmoderno manifiesta su clara defensa por el pluralismo, la existencia de muchas verdades (exaltación del relativismo), la importancia del momento presente y la fragmentación del conocimiento.

La valoración postmoderna de la existencia de diferentes formas de conocimiento se ha traducido en una devaluación del conocimiento y de la cultura. A medida que el conocimiento científico se hace cada vez más provisional, la validez del currículum basado en el saber dado y en hechos indiscutibles se hace cada vez más discutible, al igual que los fines morales de la educación vinculados a la cultura europeísta masculina. La pluralidad, la diversidad y la incertidumbre legitimarán las formas de vida derivadas de esta corriente de pensamiento al tiempo que hacen emerger nuevas identidades y nuevos discursos, como el feminismo, el ecologismo, los movimientos a favor de la paz y la superación de los etnocentrismos.

Para adecuarse a este contexto económico y cultural, las actividades formativas de la educación de personas adultas adquieren diversas formas en términos de objetivos, procesos, participantes y estructuras organizativas:

a. Una de las consecuencias de la internacionalización de la producción ha sido el aumento de la movilidad de los ciudadanos entre los diferentes países, lo que implica que la educación de las personas adultas debe hacer frente a esta nueva realidad multicultural, contribuyendo a crear un clima de paz y respeto para otras realidades culturales hasta el momento silenciadas.

b. Por otra parte, competencias que cobran especial importancia en el contexto económico actual, como la flexibilidad, la creatividad o la capacidad de iniciativa,

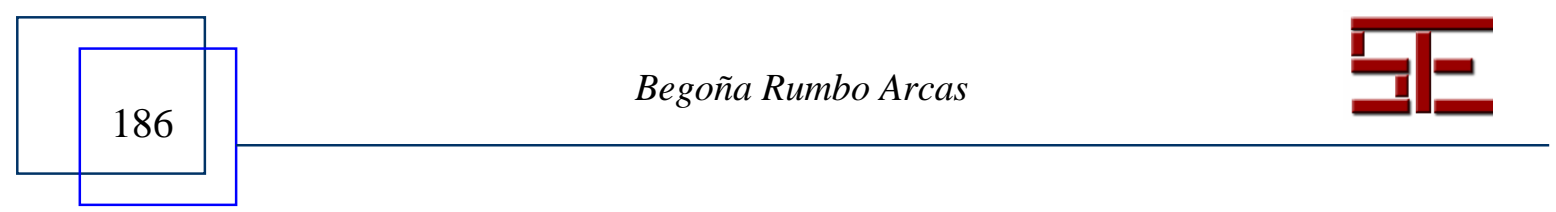




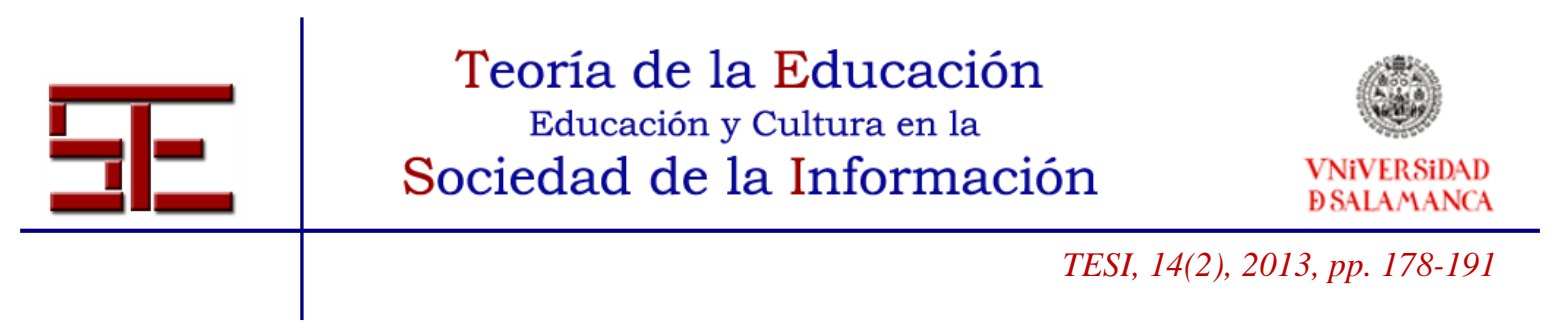

demandan una educación que capacite a las personas adultas para que tengan un mayor control de su vida laboral y les posibilite mejorar su calidad de vida. El modelo vocacional se convierte en el modelo dominante en el escenario global en donde las multidestrezas y la motivación individual se privilegian.

c. Así mismo, el efecto de la globalización ha provocado una ruptura necesaria de los límites entre las instituciones proveedoras de oportunidades de aprendizaje para las personas adultas (formales, no formales e informales). La proliferación de actividades educativas no formales ha conducido a que las actividades formales dejen de tener el monopolio para proporcionar oportunidades de aprendizaje y se desplacen a otras formas de aprender como, por ejemplo, la educación a distancia o el aprendizaje en el lugar del trabajo.

d. La revolución tecno-científica ha sido inseparable de los procesos de globalización. El conocimiento empieza a ser asimilado como información que puede ser comunicada a través de los diferentes medios electrónicos. Los recursos didácticos tradicionales (libros de texto, fichas de trabajo, etc.) no tienen mucho que hacer frente a otras modalidades de enseñanza y aprendizaje más complejas, instantáneas y atractivas, con las que les resulta difícil competir a los docentes. En esta situación, el profesorado se encuentra ante el desafío de, por una parte, ser usuario competente de tecnología y, por otra parte, ver las posibilidades didácticas que las nuevas tecnologías ofrecen para, finalmente, ser analistas críticos de las imágenes e informaciones que éstas trasmiten; porque no todas las informaciones son educativamente relevantes para el crecimiento personal y el progreso de la humanidad.

\section{REPENSAR LA EDUCACIÓN DE LAS PERSONAS ADULTAS: UNA NUEVA RACIONALIDAD}

Sin duda, la celebración postmoderna de las diferencias, los particularismos y los pluralismos ha sido uno de los discursos más atractivos para su defensa en el ámbito cultural y educativo. Pero como afirma Mayos "la condición postmoderna muestra una doble cara: de decadencia de progreso tecnológico y de decadencia humana (...); de potencia colectiva en las instituciones y de miseria en las personas; de crecimiento exponencial del conocimiento experto y de profunda degradación cultural y cívica; de enorme enriquecimiento mediático y de profundo empobrecimiento en los ciudadanos" (Mayos, 2011b, 176, paréntesis mío).

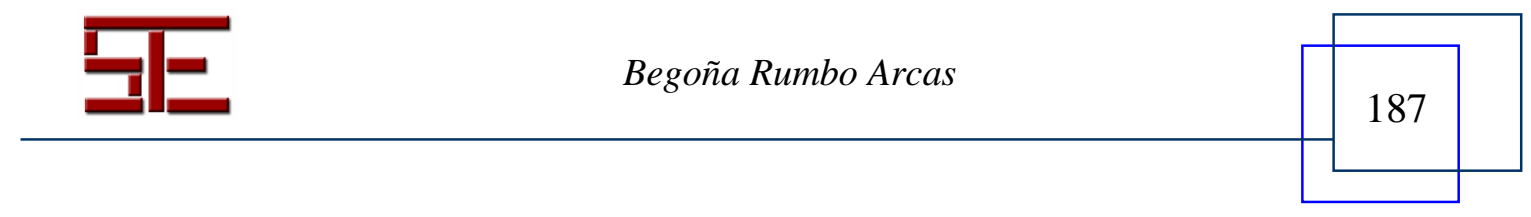




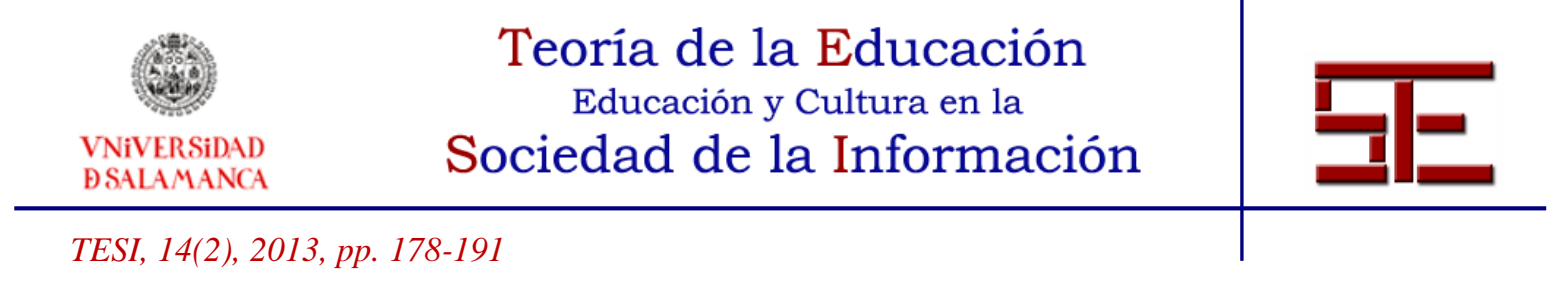

Es, precisamente, la necesidad de ser cautelosos en la defensa de la teoría postmoderna lo que nos lleva a continuación a reflexionar críticamente sobre algunos de sus más atractivos presupuestos.

Ante el dilema planteado de elegir entre los valores de la modernidad y su "discurso" educativo de la emancipación social, y la necesidad que tiene la educación de personas adultas de adaptarse a las demandas de la actual coyuntura económico-cultural, nuestra postura se sitúa en la necesidad de buscar el equilibrio entre las necesidades educativas que la sociedad actual nos impone como educadores de personas adultas y nuestros deseos en alcanzar una mayor igualdad social, porque, como Leitch (1996) argumenta, "es posible, por un lado y al mismo tiempo, distinguir tendencias que hacen de las instituciones educativas tanto factorías de conocimiento que buscan el beneficio, como la apertura de la escuela a la existencia cotidiana interesada en generar nuevos conocimientos y una crítica del statu quo" (cit.p. Edwards, 2007, 73).

En este sentido es necesario precisar que es cierto que la modernidad y su fe ciega en el progreso ha sido incapaz de resolver los problemas de la desigualdad, la violencia, la insolidaridad, el deterioro de los recursos naturales, etc.; pero la nueva condición social contemporánea tampoco está siendo capaz de resolver los problemas que se derivan de la flexibilidad económica y la crisis del Estado del Bienestar.

Por todo ello, la construcción de los discursos que gobiernan la condición social contemporánea necesitan ser leídos desde una perspectiva crítica, teniendo presente, como sugiere Andy Hargreaves (1996), que la condición postmoderna, como todos los sistemas sociales, no existe con independencia de las acciones de las personas que comprende y la constituyen. Del mismo modo que las acciones de esas personas no existen con independencia del contexto, ni de los sistemas en los que están inmersas.

Consecuentemente, la globalidad debe ser entendida, más que como la defensa de una única cultura, como un diálogo entre las culturas que persigue la tolerancia a partir del respeto a las diferencias, lo que nos exige unas mínimas bases comunes de convivencia y libertad que, si no existiesen, pudieran poner en peligro la vida de los más débiles.

Valores dominantes en la realidad de hoy, como el énfasis en los sentimientos, el esfuerzo por el placer, el individualismo y la libertad son importantes y, consecuentemente, necesitamos que la educación nos lleve a su consecución. Pero su potencial virtuosidad se limita cuando se contrapone a los valores de la modernidad, porque entendemos que no hay

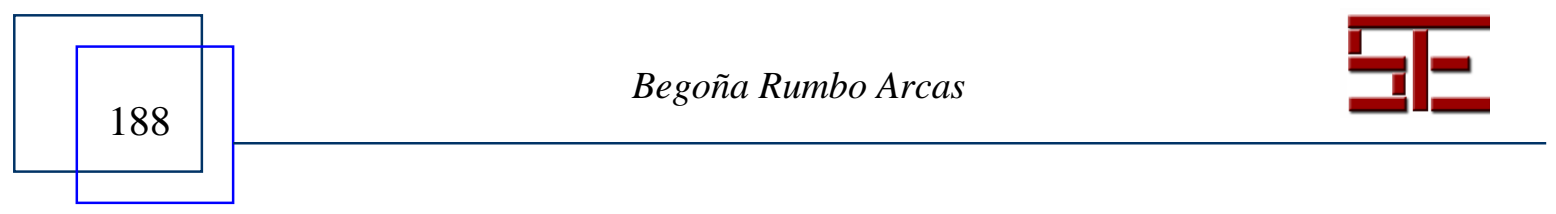




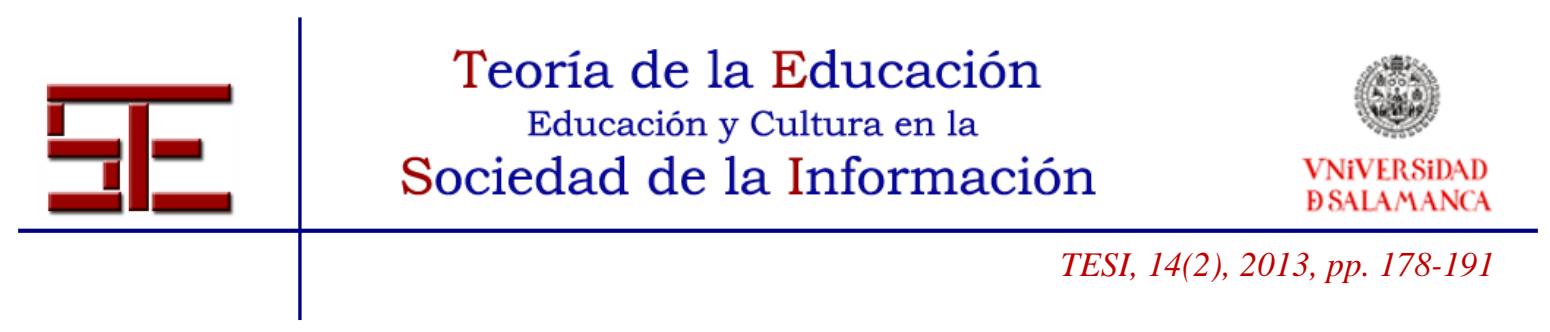

libertad sin esfuerzo, ni individuo al margen de la sociedad, ni sentimiento sin razón.

La inmediatez del presente al que nos invita la actual condición contemporánea implica que las personas humanas somos objetos en un mundo ya construido y, por tanto, nuestra participación se limita a aceptar resignados la situación vital en la que nos encontramos. Frente a esta objetividad ahistórica, la educación de las personas adultas debe ser reinterpretada desde una racionalidad crítica que busca la emancipación y el cuestionamiento de la realidad. Una realidad en la que todos somos parte y sujetos partícipes $\mathrm{y}$, consecuentemente, tenemos la capacidad para poder cambiarla y transformarla en una realidad más justa, porque el mundo lo construimos entre todos.

Como enfatiza Hargreaves (1996) el término "sociedad del conocimiento" es realmente un nombre inapropiado, debería denominarse "economía del conocimiento" porque sólo se piensa en términos de beneficios: estándares de resultados, baremos de competencias, consecución de objetivos, ocupan el tiempo de los docentes con tareas mecánicas. Por el contrario, para avanzar realmente desde una economía del conocimiento a una sociedad de aprendizaje se requiere "crear nuevos órdenes de carácter epistemológico, nuevos valores de referencia, nuevas construcciones éticas que nos den seguridad de que el manejo de un extraordinario potencial técnico no sea empleado en beneficio de unos pocos" (Subirats, 2011, 103).

En esta tesitura, la nueva educación de personas adultas no sólo debe formar a trabajadores productivos, sino que también debe contribuir al "empoderamiento ciudadano", de tal manera que las personas recobren su participación política en la vida pública y potencien las instituciones que nos proporcionan protección social, de manera que podamos alcanzar el objetivo democrático de garantizar la dignidad humana. Para ello, la educación de las personas adultas del siglo XXI debe aspirar a alcanzar los seis grandes objetivos propuestos por Ettore Gelpi (1998), esto es, la interdisciplinariedad, la interculturalidad, la intemporalidad, la internacionalidad, la intersociabilidad y la interinstitucionalidad.

\section{BIBLIOGRAFÍA}

Apple, M. (1996). Política cultural y educación. Madrid: Morata.

- (2002). Educar "como Dios manda". Mercados, niveles, religión y desigualdad. Barcelona: Paidós.

Bagnall, R. G. (2007). Good Practice in Lifelong Learning. EN D. AsPIN, Philosophical

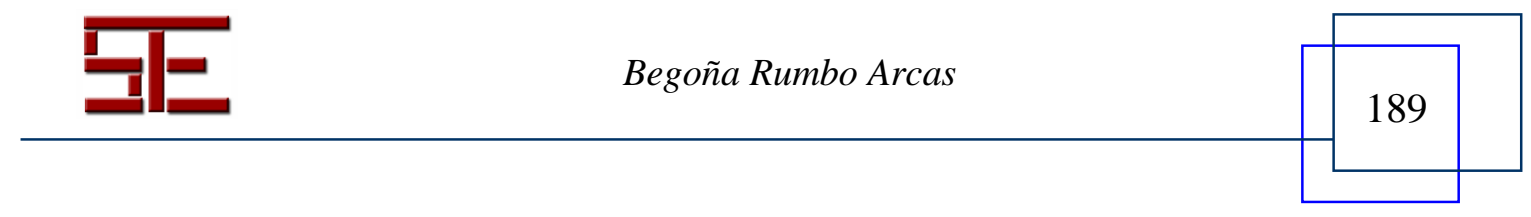




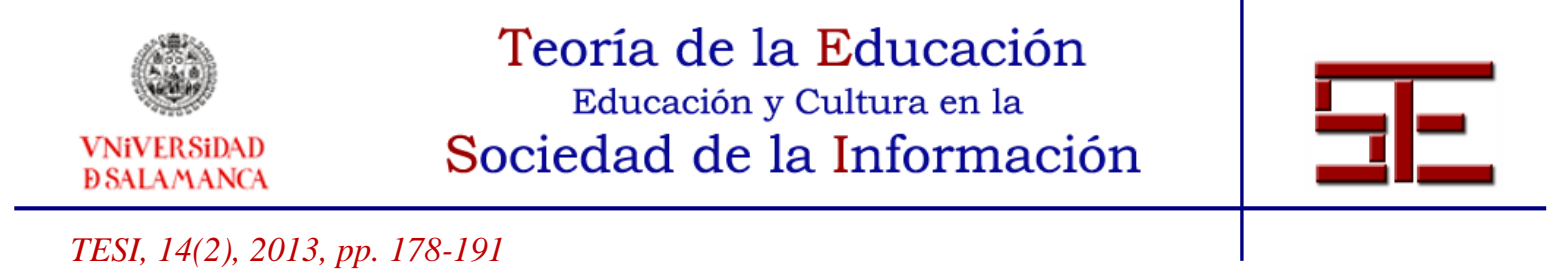

Perspectives on Lifelong Learning, (pp. 237-257). Springer: The Netherlands.

Crowther, J. (2004). In and against' lifelong learning: flexibility and the corrosion of character. International Journal of Lifelong Learning, 23, 2, 125-136.

Edwards, R. (2007). From Adult Education to Lifelong Learning and Back Again. En D. Aspin,. Philosophical Perspectives on Lifelong Learning, (pp. 70-84). Springer: The Netherlands.

Euridyce (2011). La educación formal de adultos en Europa: políticas y prácticas. Comisión Europea/MEC.

García Carrasco, J. y García del Dujo, A. (1997). Planteamiento sociopolítico de la educación de adultos en sociedades desarrolladas. En J. García Carrasco (Coord.), Educación de adultos (pp. 1-22). Barcelona: Ariel.

Gelpi, E. (1990). Educación Permanente. Problemas laborales y perspectivas educativas. Madrid: Popular.

- (1998). Identidades, conflictos y educación de adultos. Islas Baleares: Servei de Publications i Intercanvi Cientific/Diálogos.

Gimeno Sacristán, J. (1998). Poderes inestables en educación. Madrid: Morata.

Giroux, H. (1997). Cruzando límites. Trabajadores culturales y politicas educativas. Barcelona: Paidós-Ecuador.

Hargreaves, A. (1996). Profesorado, cultura y postmodernidad. Madrid, Morata.

KEMMIS, S (1999-2000). Aspiraciones emancipadoras en la era posmoderna. Kikiriki, 55-56, 4-34.

Leicester, M.; Twelvetrees, R. y Bowbrick, P. (2007). Philosophical Perspectives on Lifelong learning insights from Education, Engineering, and Economics. En D. Aspin. Philosophical Perspectives on Lifelong Learning, (pp. 258-274). Springer: The Netherlands.

Lyotard, J. F. (1996). La postmodernidad (explicada a los niños). Barcelona: Gedisa.

Mayos, G. (2011a). Dificultades para el empoderamiento de la sociedad del conocimiento.

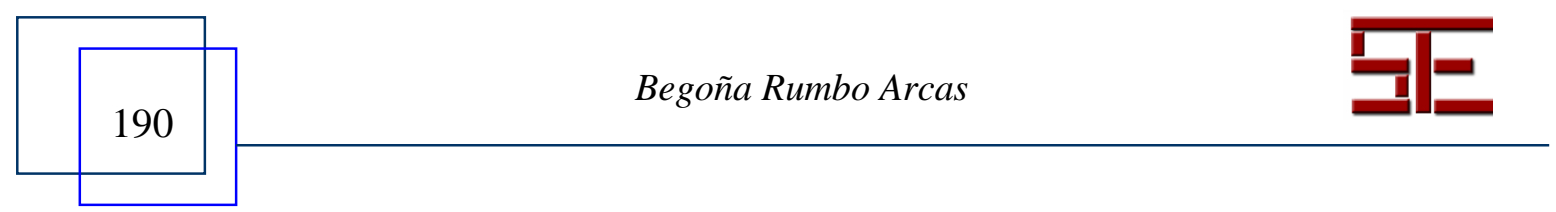




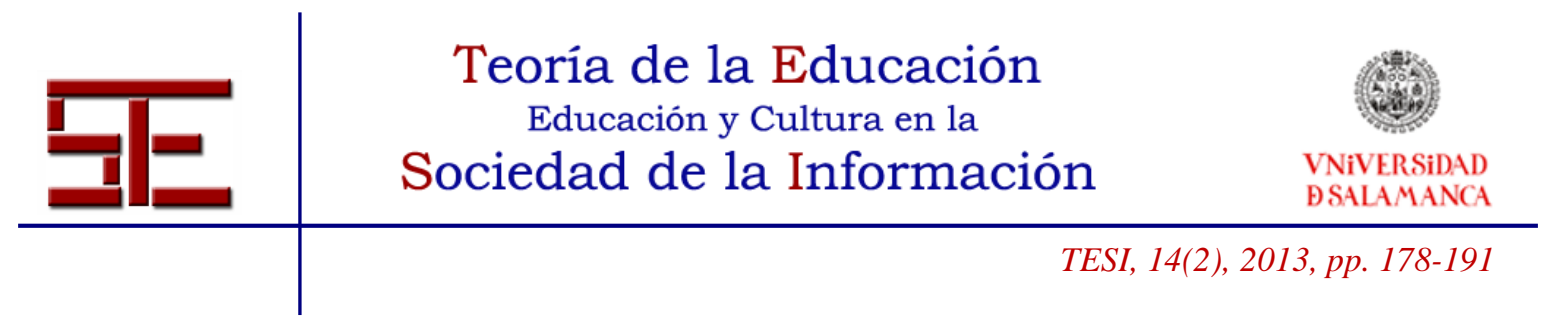

En G. Mayos y A. Brey, (Eds.). La sociedad de la ignorancia (pp. 13-45). Barcelona: Península

- (2011b). La sociedad de la incultura, ¿Cara oculta de la sociedad del conocimiento?, en G. Mayos y A. Brey, (Eds.). La sociedad de la ignorancia (pp. 167-227). Barcelona: Península

Mojab, S. (2001). Descapacitando a las mujeres inmigrantes mediante la formación. En R. Cervero, R, A.L. Wilson y Associates, Power in Practice. Adult Education and the Struggle for Knowledge and Power in Society (pp. 23-41). S. Francisco: Jossey-Bass.

Pérez Gómez, A. (1998). La cultura escolar en la sociedad neoliberal. Madrid: Morata.

Subirats, M. (2011). La sociedad del conocimiento y las dificultades de su producción, en G. Mayos y A. Brey (Eds.), La sociedad de la ignorancia (pp. 87-104). Barcelona: Península.

Torres, C. A (1996). Adult Education form Development. En A. C. Tuijnman (Ed.), Encyclopedia of Adult Education and Training (pp 213-221). Oxford: Pergamon.

Usher, R. (2007). Reading Lifelong Learning. Through a Postmodern Lends. En D. Aspin, Philosophical Perspectives on Lifelong Learning, (pp. 211-233). Springer: The Netherlands.

Usher, R., Bryant, I. \& Johnston, R. (1997). Adult Education and the postmodern challenge. London: Routledge.

Vargas Llosa, M. (2012). La civilización del espectáculo. Madrid: Alfaguara (3 ${ }^{\mathrm{a}}$ ed).

Para citar el presente artículo puede utilizar la siguiente referencia:

Rumbo Arcas, B. (2013). Tensiones y dilemas en la educación de personas adultas. Revista Teoría de la Educación: Educación y Cultura en la Sociedad de la Información. 14(2), 178-191 [Fecha de consulta: dd/mm/aaaa].

http://campus.usal.es/ revistas_trabajo/index.php/revistatesi/article/view/10219/10628

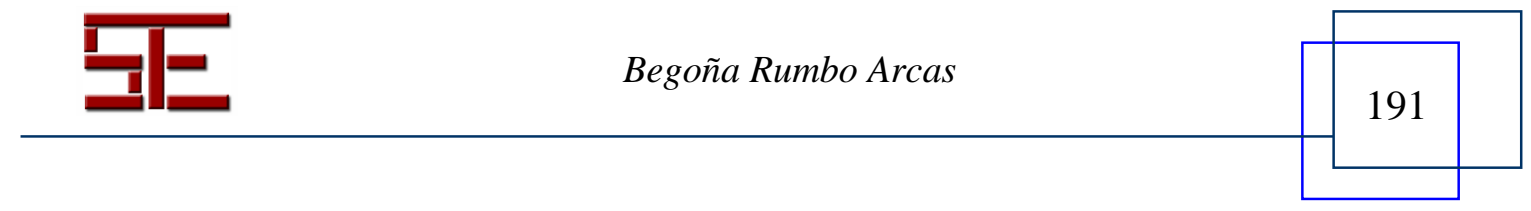

